\title{
Nanostructured Iron-Substituted Lithium-Manganese Spinel as an Electrode Material for Hybrid Electrochemical Capacitor
}

\author{
R. Lisovsky*, B. Ostafiychuk, I. Budzulyak, V. Kotsyubynsky, A. Boychuk \\ AND B. RACHIY \\ Vasyl Stefanyk Precarpathian National University, 57 Shevchenko Str., Ivano-Frankivsk, 76018, Ukraine
}

\begin{abstract}
Structure, morphology and electrochemical properties of iron substituted lithium manganese spinel were investigated. The cyclic capability of obtained materials in aqueous electrolyte was studied. The kinetic characteristics of $\mathrm{Li}^{+}$-ions charge-discharge intercalation were determined.
\end{abstract}

DOI: 10.12693/APhysPolA.133.876

PACS/topics: 68.37.Hk, 73.63.Bd, 82.45.Yz, 82.47.Uv, 82.47.Wx, 84.32.Tt

\section{Introduction}

Hybrid capacitors (HC) are one of the most promising modern electric energy power sources and can successfully replace lithium battery in many branches (electric transport, portable electronics) [1]. The performance of HC depends on the peculiarities of surface adsorption and redox reactions. Polarized electrode is typically based on different carbon materials [2]. Lithium-manganese spinel is one the best materials for redox electrode due to high ion and electron conductivity [3]. The disadvantage of these materials is a structure distortion during charge/discharge process. This is the main reason for investigations of spinel crystal structure substitution for lattice stabilization in particularly by iron cations [4]. Simultaneously this is a way for electrode material both conductivity increasing and lithium ions diffusion coefficient enlarging. The aim of the paper is investigation of ultrafine $\mathrm{LiMn}_{1.95} \mathrm{Fe}_{0.05} \mathrm{O}_{4}$ spinel as Faraday's electrode of $\mathrm{HC}$.

\section{Experimental details}

$\mathrm{Mn}\left(\mathrm{NO}_{3}\right)_{3} \cdot 6 \mathrm{H}_{2} \mathrm{O}, \mathrm{LiNO}_{3} \cdot 3 \mathrm{H}_{2} \mathrm{O}$, and $\mathrm{Fe}\left(\mathrm{NO}_{3}\right)_{3} \cdot 9 \mathrm{H}_{2} \mathrm{O}$ were used as precursors. An aqueous solution of salts in stoichiometry molar ratio have been mixed with gel formation and aging. Obtained gel was annealed at $1073 \mathrm{~K}$. Structure and morphology of the material were investigated by X-ray diffraction (XRD), scanning electron microscopy (SEM), the Mössbauer spectroscopy and low temperature nitrogen absorption. Nanoporous carbon was obtained by raw plant materials carbonisation and activations at $673 \mathrm{~K}$ during $4 \mathrm{~h}$. The electrochemical properties of material were studied with three-electrode

*corresponding author; e-mail: lesrom2000@gmail.com cells in aqueous $1 \mathrm{M} \mathrm{Li}_{2} \mathrm{SO}_{4}$ solution. The working electrode was a mixture 75 mass\% of spinel and 25 mass\% of carbon black.

\section{Results and discussion}

Thermogravimetric and differential thermal analysis showed a single phase formation in the temperature range 600-800 K with the finishing of solid state reaction at about $900 \mathrm{~K}$ (Fig. 1). The obtained materials (predicted formulae $\mathrm{LiMn}_{1.95} \mathrm{Fe}_{0.05} \mathrm{O}_{4}$ ) have spinel structure (space group $F d 3 m$ ) with lattice constant of $0.8261 \pm 0.0325 \mathrm{~nm}$ (Fig. 2). The lithium ions occupy the tetrahedral sites of spinel structure while iron and manganese are in octahedral positions. The Mössbauer spectra consist of magnetic sextet $(61 \%)$ corresponding to high-spin $\mathrm{Fe}^{3+}$ in octahedral sites and two doublets. Data analysis was performed accordingly to [5]. Major (37\%) and minor (about $2 \%$ ) doublets correspond to $\mathrm{Fe}^{3+}$ and $\mathrm{Fe}^{2+}$ ions

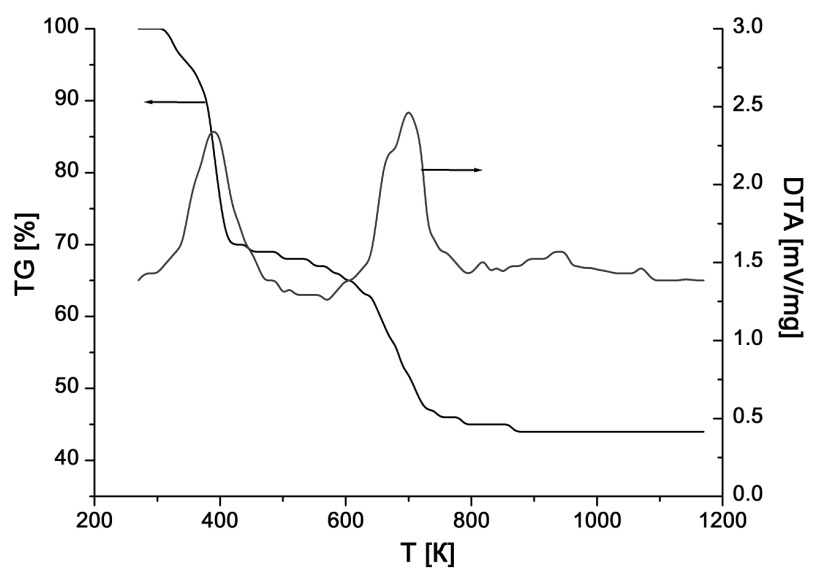

Fig. 1. TG and DTA curves of initial oxides mixture containing gel. 


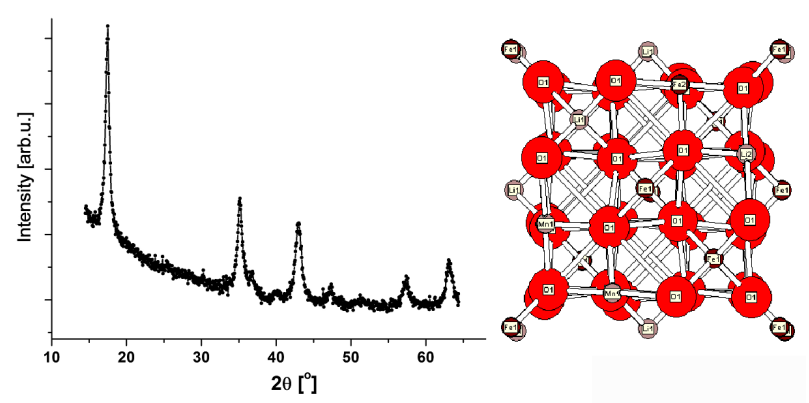

Fig. 2. X-ray diffraction patterns and visualization of $\mathrm{LiMn}_{1.95} \mathrm{Fe}_{0.05} \mathrm{O}_{4}$ lattice.

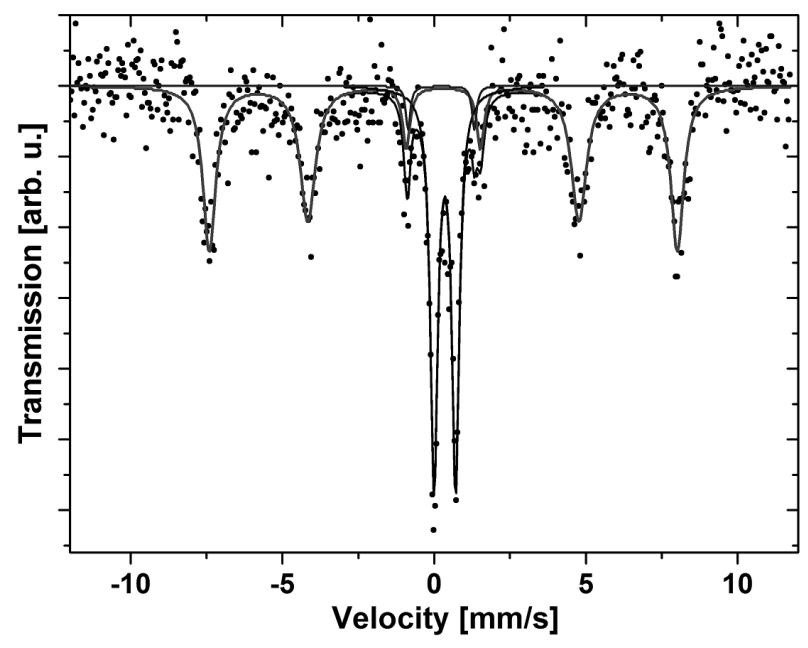

Fig. 3. The Mössbauer spectra of $\mathrm{LiMn}_{1.95} \mathrm{Fe}_{0.05} \mathrm{O}_{4}$ sample.

in octahedral oxygen coordination (accordingly to calibration of quadrupole splitting and isomer shift), respectively (Fig. 3). The presence of $\mathrm{Fe}^{2+}$ impurities is probably caused by the surface reduction during the particle sintering [6]. Average sizes of X-ray coherent scattering areas (the Scherrer equation) are about $12-15 \mathrm{~nm}$. The ultrafine particles form polycrystal agglomerates with the size about $80-100 \mathrm{~nm}$ during high temperature annealing (Fig. 4). The specific surface area (BET) was about
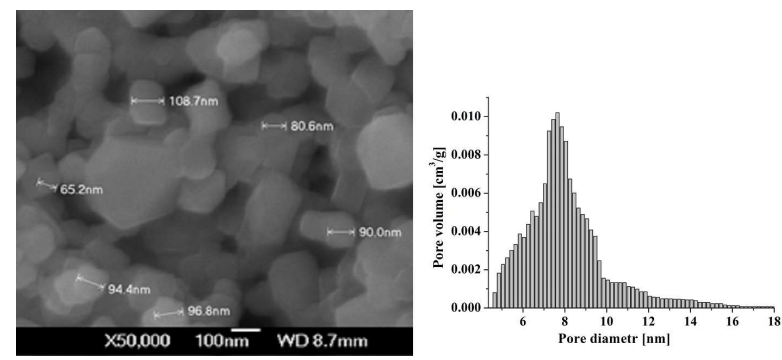

Fig. 4. SEM image of $\mathrm{LiMn}_{1.95} \mathrm{Fe}_{0.05} \mathrm{O}_{4}$ spinel particles and pore size distribution.

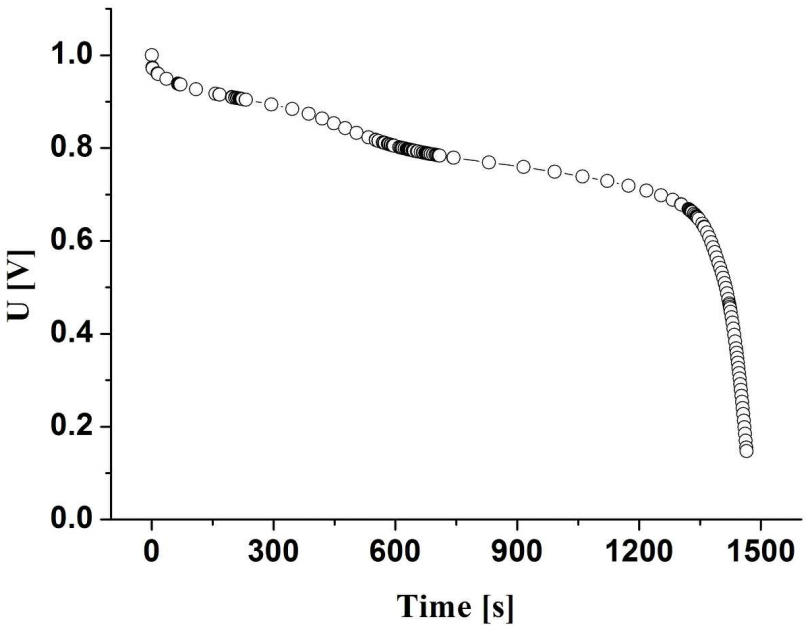

Fig. 5. Galvanostatic discharge curves of threeelectrode cell with an electrode on the base of $\mathrm{LiMn}_{1.95} \mathrm{Fe}_{0.05} \mathrm{O}_{4}$ spinel.

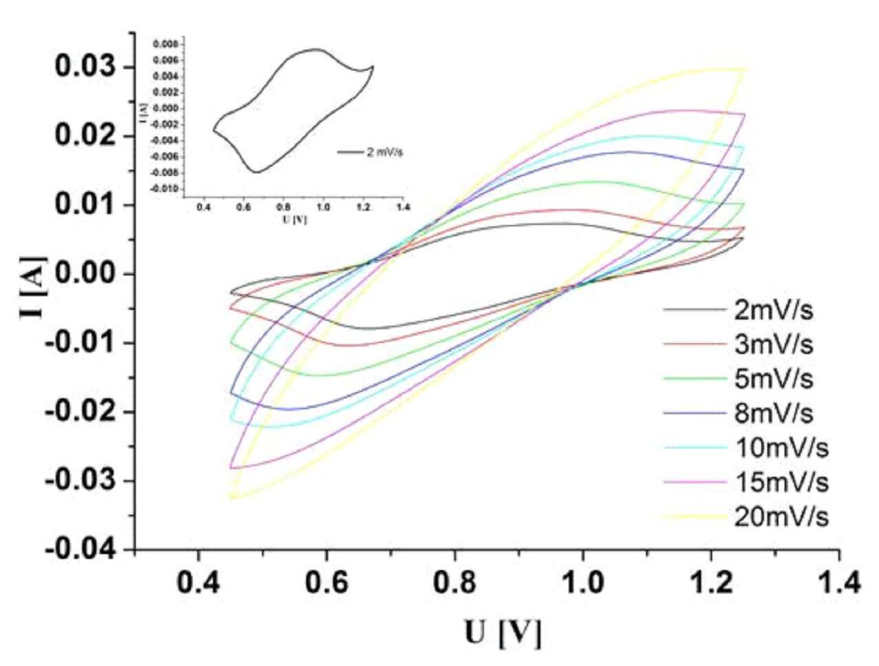

Fig. 6. CVA-curves obtained at different scanning rates $(2-20 \mathrm{mV} / \mathrm{s})$.

$32 \mathrm{~m}^{2} \mathrm{~g}^{-1}$. The pore size distribution has a maximum at about $8 \mathrm{~nm}$. The average pore sizes are close to the size of primary particle.

The discharge curves of electrode based on the obtained material demonstrate a sloping of voltage in ranges about $0.9-0.8 \mathrm{~V}$ (comparatively the chlorinesilver electrode) and capacity $13 \mathrm{mAh} / \mathrm{g}$ (Fig. 5). Cyclic voltammograms (CVA) were obtained at scan rates $(2-$ $20 \mathrm{~V} / \mathrm{s}$ ) (Fig. 6). CVA curves at low scan rates are characterized by redox peaks at $0.60-0.65 \mathrm{~V}$ which associated with reversible $\mathrm{Li}^{+}$ions intercalation. The reduction peaks shift negatively and the oxidation peaks shift positively with the scan rate increasing. The diffusion coefficient $(D)$ was calculated from the CVA data using linear approximation of $i_{p}$ vs. $\nu^{1 / 2}$ plot [7]: $i_{p}=$ $2.99 \times 10^{5}(\alpha n)^{1 / 2} A \Delta C D_{L i}^{1 / 2} \nu^{1 / 2}$ (where $i_{p}$ - peak cur- 
rent, $\nu$ - scan rate, $A$ - the electrode area, $\alpha$ - transfer coefficient, $C-$ Li-ion molar concentration in electrode, $n$ - number of electrons transferred in the redox process $(n=1), F-$ Faraday constant, $R-$ gas constant, $T-$ temperature. The obtained value of diffusion coefficient is in a range $(2.5-6.5) \times 10^{-12} \mathrm{~cm}^{2} \mathrm{~s}^{-1}$. This result indicates the 3D-arrangement of intercalated ions during the intercalation.

\section{Conclusions}

The iron substituted lithium manganese spinel $\mathrm{LiMn}_{1.95} \mathrm{Fe}_{0.05} \mathrm{O}_{4}$ synthesized by sol-gel method is the promising electrode materials for hybrid capacitors. The presence of $\mathrm{Fe}^{2+} / \mathrm{Fe}^{3+}$ redox couples and increased accessible surface area to electrolytes are the additional factors to enhanced pseudocapacitive contribution for charge storage mechanism. $\mathrm{Li}^{+}$ions diffusion coefficient slightly depends on the scan rate and changes in the range of $(2.5-6.5) \times 10^{-12} \mathrm{~cm}^{2} \mathrm{~s}^{-1}$.

\section{References}

[1] K. Shivarama Krishna, K. Sathish Kumar,Renew. Sustain. En. Rev. 52, 907 (2015).

[2] B.I. Rachiy, I.M. Budzulyak, V.M. Vashchynsky, N.Ya. Ivanichok, M.O. Nykoliuk, Nanoscale Res. Lett. 11, 18 (2016).

[3] Ting-Feng Yi, Jie Mei, Yan-Rong Zhu,J. Power Sourc. 316, 85 (2016).

[4] Li Yang, Ma Boyu, Chen Ning, Lu Jun, Cao Guohui, Physica B Condens. Matter 405, 4733 (2010).

[5] V.O. Kotsyubynsky, V.V. Moklyak, A.B. Hrubiak,Mater. Sci-Pol. 32, 481 (2014).

[6] B. Ostafiychuk, I. Budzulyak, T. Boychuk, R. Ilnytskiy, V. Moklyak, A. Boychuk, Metallofiz. Noveishie Tekhnol. 37, 1713 (2015).

[7] P. He, X. Zhang, Y.G. Wang, L. Cheng, Y.Y. Xia, J. Electrochem. Soc. 155, A144 (2008). 